\title{
Importância e Atualidade do Direito Romano *.
}

\author{
Rubens Limongi França \\ Docente Livre de Direito Civil na Faculdade \\ de Direito da Universidade de São Paulo.
}

\begin{abstract}
Sumário: I. O Direito Romano na formação do Direito Moderno. a) Preliminar sôbre a História do Direito Romano. b) As Raízes Romanas do Direito Moderno. II. $O$ Direito Romano na Formaşão do Direito Luso-Brasileiro. c) Das Origens às Ordenações de D. Filipe. d) Das Ordenações ao Código Civil. III. O Direito Romano no Regime do Código Civil.
\end{abstract}

Propomo-nos neste trabalho, à face das injustificáveis investidas com que o Direito Romano se tem defrontado, a ponto de haver uma corrente que o deseja proscrever do currículo do bacharelado, cuidar da importância e da atualidade da matéria. Da importância, porque, conforme procuraremos demonstrar, não é possível compreender o Direito Moderno sem uma constante referência à suas raízes românicas; e atualidade, porquanto, ainda em nossos dias, o Direito Romano continua a constituir elemento integrante, dos mais significativos, do sistema jurídico em vigor.

* Aula ministrada, na regência de Direito Romano, do Curso Noturno da Faculdade de Direito da Universidade de S. Paulo, em 8 de março de 1965. 
Assim, a exposição do tema se dividirá em três partes: $1 .^{a}$ - O Direito Romano na Formação do Direito Moderno; $2 .^{a}$ - O Direito Romano na Formação do Direito Luso-Brasileiro; 3. ${ }^{a}$ - O Direito Romano no Regime do Código Civil.

Passemos a examiná-las.

\section{O Direito Romano, na formação do Direito Moderno.}

Nesta primeira parte serão abordados dois itens: a) Freliminar sôbre a História do Direito Romano; b) As Raizes Romanas do Direito Moderno.

a) Preliminar sôbre a História do Direito Romano.

Se é verdade que, conforme afirmou STERnberG, não é passível em tese fazer Direito sem História, o que redundaria forçosamente em desordem e destruição, (Introducción a la Ciencia del Derecho, p. 32, Barcelona, 1940), a certeza desta ponderação avulta em gravidade quando se trata de um tema como o presente, de específica natureza histórico-jurídica.

Daí esta preliminar em que, ràpidamente, 'desejamos assinalar, no evolver da história do Direito Romano, a fase ou as fases em que, de maneira mais significativa, se aprofundam as raízes do Direito Moderno, e, em meio a êste, o Direito Luso-Brasileiro.

Como é sabido, costumam os especialistas expor a evolução jurídica de Roma segundo duas perspectivas, paralelas e complementares uma à outra, denominando-as História Externa e História Interna.

A História Externa é um passar de olhos, por assim dizer, de fora para dentro, por meio do qual se examina mais pròpriamente o suceder dos fatos que respeitaram às transmudações do Estado, do govêrno romano, e as inelutáveis conseqüências que daí vieram para a formação do 
seu sistema jurídico. Assim, a História Externa do Direito Romano tem correspondência exata com a exposição da sua História Política, onde se deparam quatro períodos fundamentais: o Periodo Régio, que vai desde a fundação de Roma (754 a.C.) até a expulsão dos Reis (510 a.C.); o Período da República, que se prolonga até vésperas da Era Cristã, com a elevação de Otaviano Augusto, (27 a.C.); o Período do Principado, instituído por êste soberano e que se mantém até a morte de Alexandre Severo (235 d.C.); e o Período da Monarquia Absoluta, o qual, depois de quase cinqüenta anos de gravíssima transição política - a da Anarquia Militar - tem início com a ascenção de DiocleCIANo (284 d.C.), para só terminar trezentos anos depois, com a invasão dos Godos, alguns anos em seguida à morte dessa figura extraordinária da História Geral e da História do Direito - o Imperador Justiniano, autor do Corpus Juris Civilis (565 d.C.).

Já a História Interna é a busca de uma perspectiva de dentro para fora, é a reconstituição do desabrochar das instituições jurídicas, em todos os seus movimentos que vão do germe à corola, e da corola ao fruto sazonado.

Interessam aí menos os fatos políticos do que os eventos de natureza jurídica pròpriamente dita, não obstante a constante interdependência entre uns e outros.

Assim, os períodos da História Interna nem sempre têm correspondência exata com os da História Externa, e enquanto quádrupla é a divisão desta, a divisão daquela é tríplice, pois aí se divisam com nitidez três épocas em que o Direito aparece com características bem distintas: o período do Jus Civile, o do Jus Gentium e o Post-Clássico.

o primeiro corresponde a todo o período régio e se prolonga pelo primeiro século da República, até a Lei das YII Tábuas, promulgada em 410 a.C.; o segundo abrange todo o restante da República, o Principado e a Anarquia Militar; e o terceiro coincide com a Monarquia Absoluta.

O período do Jus Gentium, um vastíssimo lapso de quase setecentos anos, subdivide-se em três fases: primeira, 
a que chamaremos da universalização do Direito para cuja balisa final propomos a data de 95 a.C., quando foi elevado a cônsul o primeiro dos jurisconsultos que já se pode incluir na fase seguinte, Quintus Mucius Scaevola; a segunda, a fase clássica do Direito Romano, que bem se poderia denominar a fase áurea, como também a fase científica, cujo término se pode fixar em 239 d.C., data da morte de MoDEsTino, o último dos grandes jurisperitos, discípulo de Ulpiano; a terceira, a fase da estagnação do Direito Romano, como conseqüência da Anarquia Militar.

Ao longo dêstes treze séculos, pelos quais se estende, nas duas perspectivas acima indicadas, a História una e incindível do Direito Romano - que de transformações não haveriam de, necessàriamente, experimentar as instituições jurídicas de Roma, seguindo-lhe a evolução dos costumes, do tipo de vida, das possibilidades econômicas, do aprimoramento da cultura! Fácil é imaginar que uma coisa era o Direito ao tempo de Rômulo, líder de uma grei de lavradores e pastores, e outra o Direito ao tempo de Julio CESAR - quando, depois de sete séculos da sua fundação, a Urbe se constituira em senhora da Economia e da Cultura do mundo Ocidental. Do mesmo modo que ainda bem diverso haveria de ser, à época de Constantino ou de TeoDósю, o sistema jurídico de um Império que, tendo repudiado um politeismo onde Petronio vira mais deuses do que homens (Apud A. C. Matroso, História da Civilização, vol. I, p. $425,3 .^{\mathrm{a}}$ ed.), adotara os princípios estáveis e equilibrados da religião Cristã.

Infelizmente, não é êste o lugar azado, a despeito do grande interêsse, para o exame dos caracteres fundamentais dos diversos períodos dessa evolução das instituições de Roma, desde o exoterismo e o formalismo jurídico-religioso, do tempo do Jus Civile, desde os primeiros plebiscitos, os pródromos do Direito Pretoriano, e as primeiras concessões ao Direito Estranho, da fase da Universalização, até os esplendores da época Áurea, quando Paulo e Papiniano, Ul- 
PIANo e Celso, e tantos outros mestres, conseguiram alcançar, como nunca, na História, no dizer de Contardo Ferrini, "l'esercizio della più squisita logica giuridica" (Manuale di Pandetti, p. 3, 5. ${ }^{\mathrm{a}}$ ed.).

Basta entretanto assinalar que, a despeito da decadência política de Roma ao tempo da Monarquia, não se pode dizer que o Direito tenha decaído, porquanto é no Período Pós-Clássico, não obstante a falta de grandes juristas criadores, natimortos, em virtude do monopólio jurídico do Imperador, que se compilou, por vontade de Justiniano e por obra de Triboniano e seus auxiliares, o mais estupendo monumento jurídico de todos os tempos, raiz, alicerce e sustentáculo de todo o sistema jurídico Ocidental - o Corpus Juris Civilis.

Essa obra é composta de três partes: o Digesto ou Pandectas, o Código e as Novelas.

No Digesto se encontra uma seleção dos mais sábios ensinamentos jurídicos exarados em treze séculos de $D i$ reito Romano, e especialmente pelos mestres da fase clássica. Para se ter uma idéia da obra ingente que se levou a efeito, basta dizer que os seus elaboradores, em apenas três anos, reduziram dois mil volumes com mais de três milhões de parágrafos, a apenas cinqüenta livros com 150.000 parágrafos (V. de nossa autoria, - Brocardos IUrídicos - As Regras de Justiniano, p. 37, ed. 1961). Tão extraordinária essa obra pareceu ao Imperador que não trepidou em denominá-la — "proprium et sacratissimum templum justitiae"!

O Código é a compilação das Constituições dos soberanos e as Novelas as novas leis que, com grande sabedoria, bafejado pelos sentimentos cristãos, o próprio Justiniano veio a promulgar posteriormente.

A partir da morte de Justiniano, a História do Direito Romano se dicotomiza. De um lado, segue uma linha ininterrupta, que vai até a queda de Constantinopla nas mãos dos turcos em meados do século $\mathrm{XV}$, formando o que se 
denomina Direito Romano Bizantino. Do outro lado, segue um destino que se poderia chamar agônico (na acepção erudita do têrmo, porque agonia quer dizer luta), em que os monumentos jurídicos do grande Povo sofreu os embates das invasões e do domínio bárbaro, entrando assim em decadência, para só no século XI, já nos albores da civilização moderna, com a formação dos primeiros Estados dos tempos atuais, revivescer no ensinamento dos Glosadores e Post-Glosadores, e especialmente da Escola de Bolonha.

\section{b) As Raizes Romanas do Direito Moderno.}

Daí a sintese de Rudolph von Jhering ( $O$ Espírito do Direito Romano, vol. II, p. 11, Rio, 1943), segundo o qual - "Três vêzes Roma ditou leis ao mundo e três vêzes serviu de traço de união entre os povos: primeiro, pela unidade do Estado, quando o povo romano ainda se achava na plenitude do seu poderio; depois, pela unidade da Igreja, desde o início da queda do Império; e, finalmente, pela unidade do Direito, ao ser êle adotado, durante a Idade Média".

Com o devido respeito, pedimos licença para fazer uma observação ao ensinamento do mestre. Na verdade, não foi apenas por três, senão por quatro vêzes que Roma ditou normas para a Humanidade. Pois efetivamente uma quarta vez passou a existir. Foi quando, ao atingir o Direito Moderno e amadurecimento que repontou nos Códigos Austríaco e de Napoleão, e em tantos outros que se lhes seguiram, e à face mesmo do total repúdio dos novos legisladores - à maneira da Fênix mitológica, que renascia das próprias cinzas, alí permaneceu, na linguagem técnica, na grande parte das instituições, na divisão da matéria, no modo de raciocinar, e na própria essência da mentalidade juridica - o espírito do Direito Romano.

Com efeito, basta lembrar que todo o Direito Civil latino-americano é de formação substancialmente românica, 
desde o seu código mais antigo, que é o do Haiti, um dos primeiros dos que se seguiram ao de Napoleão, pois data de 1826, até o mais recente, a saber, o novo Código Civil do Perú, promulgado em 1957.

Do mesmo modo, tôda a Europa Ocidental, exceção feita dos países da Cammon Law, abebera-se fartamente nas fontes justinianéias, já no que tange aos ordenamentos de influência germânica, cujo padrão é o Código da Áustria, de 1810, já no que concerne aos sistemas de inspiração francesa, cujo protótipo é o Código de Napolão.

Na própria Ásia, não puderam deixar de se render à superioridade do espírito e da técnica jurídica legada pelos Romanos, codificações como a da China e a do Tonkin, de feição nìtidamente francesa, do mesmo modo que o próprio Código do Japão que, exclusão feita do livro da Família, hauriu a ciência da Urbe por intermédio do Código Alemão. (V Code Civil Chinois, ed., de Ho Tcheng-Chan, - Changai-Paris, 1931; The Civil Code of Japan, ed. de W. J. SEBALD, Londres, 1934; Code Civil Allemand, ed. de R. DE LA Grasserie, Paris, 1897; Code Civil (de Napoleão), in Les Cinq Codes, Paris, 1898; Code Civil Géneral Autrichien, ed. M. Dovcet, Paris, 1947).

Enganosa, portanto, é a orientação de René Dayid, quando, no seu Tratado de Direito Civil Comparado, denomina, a êsse grupo de ordenamentos, "sistema francês". $\mathrm{Na}$ verdade, não só dêle participam legislações que receberam influência do Código Austríaco, cujos trabalhos preparatórios, sob Maria Thereza, é muito anterior ao do Código Napoleônico, como ainda, e sobretudo, o espírito que os informa não é o francês, senão o românico, do qual a codificação francesa é uma simples sequela.

Bem mais correta, neste particular, é a lição do Prof. Vicente Ráo, quando em sua grande obra $O$ Direito e a Vida dos Direitos (Vol. I, p. 101) rotula a êste conjunto de códigos com a expressão - "sistema romano". Ora, por outro lado, o simples enunciado destas duas palavras - sistema roma- 
no - são o suficiente para demonstrar o quanto deve o Direito Moderno (pois dos sistemas atuais é êste o mais importante) em sua formação, ao preciosíssimo e inigualável legado das compilações justinianéias.

\section{O Direito Romano na formação do Direito Luso-Brasileiro.}

Examinada a influência, ou, melhor dizendo, a presença do Direito Romano no Direito Moderno, passaremos a cuidar da particularização dêsse fato, no que concerne ao Direito Luso-Brasileiro.

A exposição dêste aspecto da matéria se desdobrará em dois itens: dos quais, no primeiro, ràpidamente embora, se preḋende examinar o papel do Direito Romano no sistema português, desde as origens mais remotas até as Ordenações de D. Filipe; e, no segundo, o evolver dêsse papel a partir daí até o Código Civil, quando o Direito Civil Brasileiro atinge feição nacional definitiva.

a) Das Origens às Ordenações de D. Filipe.

Quando a província romana da Lusitânia caiu nas mãos dos Bárbaros, aí vigiram as suas Leis, especialmente o Código Euriciano, dos Godos, e o Código de Alarico II, dos Visigodos.

Mas se é certo que o próprio Código de Euriciano se ressentia já da influência dos textos romanos, não é diverso o que se dá com o ordenamento visigodo, estruturado que foi com elementos dos Códigos Teodosiano, Hermogeniano e Gregoriano, bem assim com subsídios emprestados às Sentenças, de Paulo e às Institutas de Garo.

Com o retôrno do domínio godo, sob LeovigiLdo, restaura-se o Código Euriciano, cuja vigência perdurou até o domínio dos Sarracenos, com a redação que lhe deu RecesvinDo, no século VII (v. Paulo Merea, Estudos de Direito Visigótico, p. 206, ed. da Acta Universitatis Conimbrigensis, 
1948; Mello Freire, Historiae Juris Civilis Lusitani - Liber Singularis, cap. I, \& xxviII, Coimbra, 1853).

$\mathrm{E}$ se, durante todo êsse grande lapso de tempo em que, nas profundezas das Dark Ages, se delineavam os primeiros traços da feição de um grande povo, não se pode afirmar que, mesmo nessa fase embrionária, o Direito Lusitano se tenha desligado alguma vez do cordão umbelical das fontes romanas, o certo é que, após a independência do Condado Portucalense, a presença da codificação justinianéia ganhou foros de definitiva, graças à fundação, em fins do século XIII, da Academia de Lisboa, onde oficialmente se inaugurou o estudo do Direito Romano.

Com o Mestre de Aviz, instauraram-se, juntamente com uma nova dinastia, os Estudos Gerais de Coimbra, e é neste novo cenário da História lusa que exsurge a respeitabilíssima figura de um grande discípulo de Bártolo, o inolvidável IOÃo DAS Regras, cujos profundos conhecimentos de lógica jurídica e dos textos românicos influiram decisivamente na formação, de elevadíssimo teor, a êsse tempo mais alto que o de qualquer outro país, do sistema jurídico português.

Tendo vertido para o vernáculo o Código de Justiniano com as glosas de Acursio e de Bártoro, preparou e tornou possivel a elaboração dêsse grande monumento jurídico as Ordenações de $D$. Afonso $V$ - que não é apenas o primeiro código luso, senão também o primeiro de tôda a Europa e que antecedeu de mais de três séculos os demais ordenamentos das nações modernas (V. Ordenações de D. Afonso V, Ed. de Coimbra, 1789).

Em princípios do século XVI, recém-descoberto o Brasil, publicam-se as Ordenações d'El-Rei D. Manuel.

E se do Código Afonsino disse bem o Conselheiro Ribas não ser possível entender-se sem o auxílio dos textos justinianeus (Pibas, Curso de Direito Civil, p. 93), a remissão a êles, nas Ordenaçôes Manuelinas, é expressa, como parte, integrante do sistema. 
Com efeito, numa linguagem que parece mais próxima de nós, que a dos dois séculos subseqüentes, por isso que despida dos atavios do seiscentismo, aí se lê no Livro II, Título V, êste mandamento singelo e direto, de um pragmatismo que se diria contemporâneo: "E quando o caso de que se trauta nom for determinado por lei: estilo: ou costume do reyno: mandamos q seja julguado: sendo materia que tragua pecado por os sanctos canones. E sendo materia que nom tragua pecado: mandamos que seja julguado polas leis imperiaes: posto que os sacros canones determinem o contrairo: as quaes leis imperiaes: mandamos somente guardar pola boa razam em que sam fundadas". (V ed. de João Crõberguer, Sevilha, 1539).

A oficialização expressa do romanismo como elemento integrante do sistema normativo continuou a encontrar éco sete décadas após, com as Ordenações de D. Filipe, datadas de 1603 , em cujo L. III, Tit. 64, princípio (Edição de CÂNdido Mendes de Almeida, $14 .^{a}$ ed., p. 664,1870 ) se lê determinação onde é repetido o teor do preceito manuelino.

\section{b) Das Ordenações Filipinas ao Código Civil.}

Tão reiterada consagração oficial dos textos justinianeus deu azo, no século xvir e na primeira metade do século xviIr, a verdadeiros abusos do romanismo, a ponto de, segundo noticiam os autores, se preterirem as leis pátrias pelas imperiais.

Esta a razão pela qual, eñ 18 de agôsto de 1769 , sob a inspiração do Conde de Oeyras, depois Marquês de Pombal, a que se passou a chamar Lei da Boa Razão trouxe o célebre mandamento de que as determinações do Corpus Juris Civilis só se aplicassem "pela boa razão em que são fundadas" (v. Correia Telles, Comentários à Lei da Boa Razão, in Auxiliar Jurídico, p. 453, in fine). No que foi secundada pelos Estatutos da Universidade de Coimbra, L. II, tit. 2, cap. 3, par. 5, onde se diz que - "O Direito Romano pode obter força e autoridade de lei, em suplemento do Pátrio, 
onde se não estendem as providências das Leis Nacionais, e quando é fundado na Boa Razão, que lhe serve de único fundamento" (Estatutos, edição original de 1772).

Quando da proclamação da Independência do Brasil, foi com êsse caráter que o Direito Romano passou a integrar o sistema brasileiro, e, não obstante a promulgação do Código Português, em 1867 (v. Edição de Cardoso Paul, Pôrto, 1879) que antiquou as Ordenações e leis posteriores, entre nós, os velhos diplomas lusitanos continuaram a vigir, inclusive o Código Filipino, revogados que foram, tão sòmente, em 1916, pelo art. 1807 do Código Civil Brasileiro.

É assim, pois, que a Consolidação Carlos de Carvalho, já de 1899 , no art. 5 do título preliminar, entre as fontes de caráter subsidiário indica expressamente - "o direito ro. mano justinianeo, conforme à boa razão ou direito natural, apurado pelo uso que fazem dêle as nações civilizadas e pela lição dos jurisconsultos" (Carlos de Carvalho, Nova Consolidacẫo das Leis Civis, 1899).

Daí, a êsse tempo, afirmar o Conselheiro Ribas, no seu magistral Curso de Direito Civil: "O conhecimento profundo e completo do Direito Pátrio é impossivel sem que se firme nas largas bases do Direito Romano; não só porque é neste que se encontram as razões históricas eficientes das legislações dos povos modernos, como porque é êle o mais belo, completo e majestoso monumento de sabedoria juridica, que os passados séculos nos legaram" (ANTONIO JOAQuim Ribas, Curso de Direito Brasileiro, p. 92, 3. ${ }^{\text {a }}$ ed., 1905).

\section{O Direito Romano no regime do Código Civil.}

A despeito das nossas duas primeiras Leis Magnas, a imperial, de 1824, e a republicana, de 1891, foi só com quase un século de independência política, quando da promulgação do Código Civil, em 1916, para vigorar a partir de 1 de janeiro de 1917, que alcançou autonomia a nosso Direito e a nossa Ciência Jurídica. 
$\mathrm{Na}$ verdade, o art. 1807 do Código Civil, muito mais que um encerramento de praxe, corriqueiro na técnica legislativa, trazia a própria declaração da maioridade do nosso sistema, o que foi levado a efeito nestes termos: "Ficam revogadas as Ordenações, Alvarás, Leis, Decretos, Resoluções, Usos e Costumes concernentes às matérias de direito civil reguladas neste Código".

Não quer isto dizer, entretanto, que o Direito Romano tenha perdido ou mesmo haja modificado a sua expressão como elemento integrante do sistema nacional.

É certo que o art. 7 da antiga Lei de Introdução ao Código Civil, ao indicar o que comumente se denominam "fontes" supletivas do Direito, só fazia menção à analogia e aos princípios gerais, sendo que o novo estatuto preliminar, de 1942, no art. 4, a estas só acrescentou o direito consuetudinário. Por outro lado, o preclaro Clovis Bevilaqua, autor do Ante-Projeto, nessa obra prima que é a sua Teoria Geral do Direito Civil" refere o Direito Romano, de modo expresso, como uma das "fontes subsidiárias do Direito hoje estancadas" (Clovis Bevilaqua, Theoria Geral do Direito Civil, p. 40, 2. ${ }^{\mathrm{a}}$ ed., 1929).

Não obstante, e em que pese à autoridade do eminente mestre, procuraríamos demonstrar a iniludível presença do Direito Romano em nosso sistema, a pesar e em razão mesma dos preceitos que se encontram no mais explêndido monumento jurídico da nossa História : o Código Civil. Com efeito, conforme se verá, essa participação das normas justinianéias no sistema, se verifica não só de modo indireto, se não também de maneira direta, de acôrdo com os próprios têrmos dos diplomas vigentes.

A participação indireta se dá, por sua vez, de duas maneiras: a) em virtude da etiologia dos artigos do Código em particular; e b) na consagração de conceitos básicos adotados implicitamente pelo legislador.

a) Quanto às origens dos diversos preceitos do Código em particular, o primeiro argumento nos é fornecido pelo 
próprio mestre Bevilaqua. Com efeito, se perlustrarmos os seus lúcidos e magistrais comentários ao Código Civil, aí averiguaremos que relativamente bem poucos são aquêles nos quais o autor do Ante-Projeto não nos apresenta a fonte romana da regra comentada. (Clovis Bevilaqua, Código Civil Comentado, 6 vols., 7. ${ }^{\mathrm{a}}$ ed.).

Nesse sentido, é ainda importante a contribuição do Prof. Dr. Alexandre Correia, ilustre catedrático jubilado desta Casa, em cujo Manual, escrito em colaboração com o Prof. Dr. Gaetano Sciascia, Docente da Universidade de Roma, no apêndice dos diversos capítulos, transcreve os principais textos do Direito Privado dos Romanos em conexão com os artigos do Código.

$\mathrm{E}$, finalmente, para reforçar de modo definitivo esta parte de nossa argumentação, é de se invocar a valiosa referência, feita pelo preclaríssimo mestre e magistrado, o Prof. Dr. Washington de Barros Monteiro, de que, segundo a pesquisa de Cunha Lobo, dos 1807 artigos de Código, nada menos de 1445 são de origem romana.

b) No que tange à adoção de princípios básicos implìcitamente aceitos pelo legislador, basta lembrar que, por exemplo, não apresentando o Código um conceito de obrigação, todo o seu livro III, num total de 711 artigos, gira em tôrno da definição justinianéia, inspirada num texto de PaUlo, segundo o qual obligatio est juris vinculum quo necessitate adstringimur alicuius solvendae rei, secundum nostrae civitatis jura (Inst., 3, 13, pr.; D. 44, 7, 3, pr.).

Tanto isto é certo que todos os mestres ao exporem a doutrina desta parte do nosso Direito Civil, iniciam as suas lições com a invocação do citado excerto das Institutas. Para referir apenas os três maiores dos nossos especialistas no assunto, vide o Direito das Obrigacoóes de Bevilaqua, p. 14; a Doutrina e Prática das Obrigações de Carvalho DE Mendonça, vol. I, p. 68; e as Obrigações do eminentíssimo Lacerda de Almeida, p.7. 
Do mesmo modo, no "Processo Civil", o conceito romano de ação, jus porsequendi in judicio quod sibi debetur, vem informando os nossos mais respeitáveis mestres, desde Paula Baptista, até o nosso atualíssimo Prof. Alfredo Buzaid, autor dessa obra magistral que é o Ante-Projeto de Código de Processo Civil. (Paula Baptista, Teoria e Prática do Processo Civil", p. 11, 8. ${ }^{\mathrm{a}}$ ed., 1935; Alfredo Buzaid, AnteProjeto de Código do Processo Civil, Livro I, Tit. p. 45).

$\mathrm{E}$ assim por diante.

Entretanto, como dissemos de início, não é só de maneira indireta que se nos antolha, em nosso sistema, a presença do Direito Romano. Na verdade, é ainda de modo direto que essa permanência se verifica, pois não raro os preceitos da vetusta sabedoria dos clássicos são chamados, tanto pela doutrina como pelo próprio legislador, a preencher as lacunas e a elucidar as dubiedades da lei, quando omissa ou equivoca.

E o que se comprova, primeiramente com o uso dos brocardos jurídicos, que, uma vez levado a efeito cientificamente, não se reveste do caráter acaciano que, infelizmente, não raro the empresta a cultura de algibeira dos leguleios de última hora.

Com efeito, dêles falaram com seriedade, no estrangeiro, doutrinadores de escol, como Brethe de la Gressaye e Laborde-Lacoste (Introduction Générale à l'Étude du Droit, p. 323-324, Paris, 1947) e entre nós mestres preclaros como Carlos Mamimiliano e Orlando Gomes (Hermenêutica $e$ Aplicação do Direito, $4 .^{a}$ ed., 1947; Introdução ao Estudo do Direito Civil", Rio, 1957).

Tão grande a sabedoria dos adágios jurídicos que o seu reconhecimento se transvasou das lindes da ciência ocidental, de tal forma que, na informação de Georges Ripert, em 1951, foram traduzidos para o japonês, pelo Prof. Sugyama, da Universidade de Tóquio. (Les Forces Créatrices du Droit, p. 329, nota 1, Paris, 1955). 
Entretanto, como bem pondera Carlos Maximiliano, o uso apropriado dos apotegmas só se torna possível na medida em que nos é dado relacioná-los com a sua origem e autenticidade, vale dizer na medida em que se haurem na fonte limpida do Direito Romano.

Mas não é apenas através do uso e da doutrina que o Jus Romanorum é chamado a integrar o sistema. Com efeito, o mesmo apêlo vamos encontrar no próprio texto dos diplomas vigentes, à altura em que o legislador, reconhecendo a inapelável imperfeição das leis, invoca, para complementá-las, no art. 4 da Lei de Introdução ao Código Civil, aquilo que a moderna tecnologia jurídica convencionou chamar principios gerais de Direito.

Não que êsses princípios se confundam, como deseja uma corrente italiana, com os próprios textos do Corpus Juris Civilis (V. VenzI, Notas às Istituzioni di Diritto Civile Italiano, vol. I, P. Geral, p. 81, $4 .^{\text {a }}$ ed., Florença, 1903). Mas em virtude do fato de, grande número dessas regras fundamentais da sabedoria jurídica, ter sido formulada pela vez primeira, e de modo lapidar e definitivo, pela sabedoria dos Romanos.

Para a comprovação do que afirmamos, basta lembrar a regra da impostergabilidade da norma de ordem pública, exarada por Ulpiano, no célebre texto cuja lição é a de que -privatorum conventio jus publicum non derrogat (D. 50, 17, 45, 1). Do mesmo modo, o excerto de Pomponio, onde se verbera o enriquecimento sem causa ( $O$ p. cit., p. 138; Lei nor. 206), ou o fragmento de Quinto Mucio Scaevola, segundo o qual ninguém por si pode obrigar a outrem sem fato de outrem. (D. 50, 17, 73, 4).

E, como êstes, tantos outros exemplos da mais engenhosa e lúcida sabedoria, cujo teor constitui preciosíssimo tesouro da ciência Universal, de tal forma que a sua correspondência com a verdade juridica não se transmudou nem empalideceu ao longo de quase vinte séculos! 
Não foi pois sem uma grande razão que o Prof. VANDICK LoNdres DA Nóbrega afirmou estar, como realmente está, no Direito Romano, o papel de formador da verdadeira consciência jurídica (História e Sistema do Direito Privado Romano", p. 12, 3. ${ }^{a}$ ed., 1961), pois efetivamente é com o seu estudo que nos é dado imbuir-nos do elevado espírito do bonum et aequum, sem o qual não nos será jamais possível alterum nom laedere, nem suum cuique tribuere! 